\title{
CURRÍCULO ESCOLAR E PEDAGOGIA HISTÓRICO-CRÍTICA: FORMAÇÃO EMANCIPADORA E RESISTÊNCIA AO CAPITAL
}

\author{
Julia Malanchen
}

Pós-doutora em Educação e Currículo no Institute of Education - University College London em Londres no Reino Unido.Doutora em Educação Escolar pela Universidade Estadual Paulista - UNESP/Araraquara Docente no Centro de Educação, Letras e Saúde e no Programa de Pós-Graduação em Ensino na Universidade Estadual do Oeste do Paraná UNIOESTE/Campus de Foz do Iguaçu, PR. ORCID iD: https://orcid.org/0000-0003-0921-0699. E-mail: julia malanchen@hotmail.com

\section{RESUMO}

A intenção deste ensaio teórico é o de contribuir com elementos para ampliar a compreensão sobre a etimologia da palavra Currículo e as diversas formas de interpretação, deste tema, no seu campo de estudos e pesquisas. Por outro lado, buscamos explorar alguns princípios que demarcam a definição de um currículo escolar a partir da Teoria Histórico-Crítica, diferenciando de outras teorias curriculares existentes, principalmente do multiculturalismo, que muitas vezes é interpretado equivocadamente como uma teoria marxista. Para finalizar, apontamos a necessidade de nos organizarmos enquanto classe trabalhadora numa resistência coletiva ao atual governo antinacional, que ataca a educação e a saúde pública, e ao fazê-lo, nega a ciência e a vida, aprofundando a grave crise sanitária em território nacional.

Palavras-chave: Currículo Escolar. Pedagogia Histórico-crítica. Teorias Curriculares. Multiculturalismo.

\section{SCHOOL CURRICULUM AND HISTORICAL-CRITICAL PEDAGOGY: EMANCIPATORY FORMATION AND RESISTANCE TO CAPITAL}

\section{ABSTRACT}

The intention of this paper is to contribute elements to the understanding of the etymology of the word Curriculum and the various forms of interpretation of this theme in studies and research. On the other hand, we describe some principles that demarcate the definition of a school curriculum from the HistoricalCritical Theory, differentiating it from other existing curricular theories, especially multiculturalism, which is often misinterpreted as a Marxist theory. Finally, we point out the need to organize ourselves as a working class in collective resistance to the current anti-national government, which attacks education and public health, and in doing so, denies science and life, deepening the serious health crisis in national territory .

Keywords: School Curriculum. Historical-critical Pedagogy. Curriculum Theories. Multiculturalismo.

\section{CURRÍCULO ESCOLAR Y PEDAGOGÍA HISTÓRICO-CRÍTICA: FORMACIÓN EMANCIPATORIA Y RESISTENCIA AL CAPITAL}

\section{RESUMEN}

La intención de este ensayo teórico es aportar elementos para ampliar la comprensión de la etimología de la palabra Currículum y las diferentes formas de interpretación de esta temática en su campo de estudios e investigación. Por otro lado, buscamos explorar algunos principios que demarcan la definición de currículo escolar de la Teoría Histórico-Crítica, diferenciándolo de otras teorías curriculares existentes, especialmente el multiculturalismo, que muchas veces se malinterpreta como teoría marxista. Finalmente, señalamos la necesidad de organizarnos como clase trabajadora una resistencia colectiva al actual gobierno antinacional, que ataca la educación y la salud pública, y al hacerlo, niega la ciencia y la vida, profundizando la grave crisis de salud en el territorio nacional.

Palabras clave: Currículo Escolar. Pedagogía Histórico-crítica. Teorías Curriculares. Multiculturalismo. 


\section{GÊNESE E SIGNIFICADO: UM BREVE TOUR PELA ETIMOLOGIA DA PALAVRA CURRÍCULO}

Ao pesquisar no campo da etimologia o significado da palavra currículo, verificamos que resulta da palavra latina scurrere e a mesma se desdobra em diversos significados como: ato de correr, atalho e pista de corrida. Daí surge a compreensão do currículo escolar como um caminho, um curso ou uma listagem de conteúdos que devem ser seguidos. De acordo com Barrow (1984) apud Goodson (1995, p. 31): "no que se refere a etimologia, portanto, o currículo deve ser entendido como o conteúdo apresentado para estudo".

Ainda de acordo com Goodson (1995, p.31):

A partir de sua origem latina, é importante mostrar a palavra currículo emergindo como conceito de escolarização. Segundo Hamilton e Gibbons (1980, p.15) "as palavras classe e currículo parecem ter entrado no tratado educacional numa época em que a escolarização estava se transformando numa atividade de massa".

Dando sequência a esse registro histórico sobre o desenvolvimento do termo currículo, o autor, cita Hamilton que:

(...) fornece provas adicionais provenientes de Glasgow, onde o Oxford English Dictionary situa a fonte mais antiga de curriculum em 1633. O aproveitamento do termo latino "pista de corrida" está nitidamente relacionado com o emergir de uma sequência na escolarização, porém permanece a pergunta: Porque em Glasgow? Hamilton acredita que "o senso de disciplina ou ordem estrutural absorvido no currículo procedeu não tanto de fontes clássicas quanto das ideias de John Calvin (1509-164). (HAMILTON apud GOODSON, 1995, p. 32)

Assim como se tem a confirmação dos primeiros registros do uso do termo currículo em Glasgow $^{1}$, também se confirma no texto de Goodson (1995) a primeira descrição sobre classes, que aparece nos estatutos do College of Montaign em Paris no ano de 1509.

Nesse sentido citando Hamilton (1980), Goodson (1995) sintetiza a relação entre a formação inicial das classes escolares e o desenvolvimento do termo currículo e o uso intencional desse documento para organização e padronização, do que, os distintos indivíduos que frequentavam a mesma escola, deveriam aprender:

O conceito de classe ganhou proeminência com programas sequenciais de estudo que, por seu turno, refletiam diversos sentimentos de mobilidade ascendente da Renascença e da Reforma. Nos países calvinistas (como Escócia) essas ideias encontram sua expressão, teoricamente, na doutrina da predestinação (crença de que apenas a minoria predestinada, poderia alcançar a salvação) e, educacionalmente, no emergir de sistemas de educação - nacionais sim; mais bipartidos - onde os "eleitos" (isto é, predominantemente

quem poderia pagar) eram agraciados com a perspectiva da escolarização avançada, ao passo que os demais (predominantemente pobres e da área rural) eram enquadrados num currículo mais conservador (com apreço pelo conhecimento religioso e pelas virtudes seculares. (HAMILTON, 1980 apud GOODSON, 1995, p 32-33).

\footnotetext{
${ }^{1}$ Universidade de Glasgow - Escócia hoje parte do Reino Unido
} 
Após essas afirmações, o autor, complementa que com a instituição de um currículo, confirma-se a intenção de se determinar e diferenciar a formação dos indivíduos, e de que, concomitante a sua organização e uso, foram sendo distribuídas as matérias/disciplinas escolares. Desse modo, Goodson (1995) destaca uma relação intrínseca entre classes escolares, currículo e disciplinas em sua gênese. Mais recentemente as pesquisadoras do currículo no Brasil, Lopes e Macedo² (2011, p. 19) afirmam que:

Indo dos guias curriculares propostos pelas redes de ensino àquilo que acontece em sala de aula, currículo tem significado, entre outros, a grade curricular com disciplinas/atividades/e cargas horárias, o conjunto de ementas e os programas das disciplinas/atividades, os planos de ensino dos professores, as experiências propostas e vividas pelos alunos. Há, certamente, um aspecto comum a tudo isso que tem sido chamado de currículo: a ideia de organização prévia ou não, de experiências/situações de aprendizagem realizada pelos docentes/redes de ensino de forma a levar a cabo um processo educativo.

Por isso é comum no campo da educação escolar, a palavra currículo ser utilizada pra designar o programa de uma disciplina, grade curricular de um curso, uma lista de conteúdos e objetivos a serem alcançados, ou como na atualidade no Brasil uma lista de competências para ser trabalhada e desenvolvida com alunos da educação Básica. (BRASIL, 2017; BRASIL, 2018) e na formação inicial de professores (BRASIL, 2019) e Formação Continuada (BRASIL, 2020).

Destacamos a partir dessa breve ${ }^{3}$ retomada sobre a gênese e o uso da palavra currículo, que na área das pesquisas realizadas no

\footnotetext{
${ }^{2}$ Esclarecemos que as autoras são pesquisadoras da área do currículo, mas não a partir da concepção histórico-crítica.

${ }^{3}$ Para saber mais ver: SAVIANI, N., (2000).
}

âmbito do tema, encontramos duas linhas principais de estudos desenvolvidos, conhecidas como: história do currículo e estudos curriculares. A história do currículo como afirma Nereide Saviani (2000, p. 18; 20):

(...) não se separa da
história geral da educação
no país a que se refere (e,
desta, no mundo), a qual,
por sua vez, não se separa
do ramo mais amplo da
história cultural e
intelectual. [...] [...] É
necessário, pois, que o
estudo da história do
currículo compreenda
tanto a análise da
evolução do termo, desde
seu surgimento no
vocabulário pedagógico (e
os significados a ele
atribuídos), como também
os contextos de seu
emprego e suas múltiplas
implicações na vasta rede
de relações inerentes à
atividade educacional a
que ele se refere.

Quando nos referimos à história do currículo, como aponta Nereide Saviani (2000), nos remetemos a autores ou obras clássicas que contribuíram com o pensamento pedagógico e são estudados muitas vezes na história da educação, na didática geral, nas disciplinas escolares, psicologia educacional, ou na filosofia da educação, etc., tais como: João Amós Comênio, Jean-Jacques Rousseau, o Ratio Studioriun da Companhia de Jesus, Friedrich Froebel, Celestin Freinet, John Dewey, Johann Heinrich Pestalozzi, Jean Piaget, Johann Friedrich Herbart, Carls Rogers, Anton Makarenko, Lev Vigotsky, Maria Montessori, Moisey Pistrak, Paulo Freire, Fernando Azevedo, Anísio Teixeira, Peter Mclaren, Michael Young e Dermeval Saviani, etc. Esses e outros pensadores, produzem e influenciam em teorias pedagógicas que de algum modo, apontam para um pensamento curricular, isto é, uma teoria curricular, ancorada numa dada compreensão de sociedade, ser humano, escola e conhecimento escolar.

$\mathrm{O}$ que queremos destacar, a partir do parágrafo anterior, é que existem diversas perspectivas e arcabouços históricos para se entender currículo. Nesse artigo, debateremos 
essas questões, traçando uma linha de coerência ideológica com a Pedagogia histórico-crítica, que por sua vez ancora-se em pressupostos filosóficometodológicos do Método Materialista Histórico e Dialético.

Enfatizamos que é de suma importância saber identificar em diferentes momentos da história do nosso país os fundamentos hegemônicos que norteiam intencionalmente as teorias pedagógicas e seus currículos escolares, e assim, compreender por que essas teorias não contemplam aos interesses e necessidades da classe trabalhadora usuária da escola pública.

Por fim, temos por objetivo expor os principais elementos das teorias curriculares existentes e debatidas até o momento de forma resumida ${ }^{4}$, para na sequência, diferenciar a concepção Histórico-Crítica, das mesmas.

\section{TEORIAS CURRICULARES: DO TECNICISMO E CONSERVADORISMO AO NEGACIONISMO FUNDAMENTADO NO MULTICULTURALISMO}

$O$ desenvolvimento da questão curricular, como objeto de estudo e de organização mais sistemática da área, apareceu primeiramente nos Estados Unidos na década de 1920. Pelas leituras realizadas (SAVIANI N., 2000; SILVA 2009; LOPES; MACEDO, 2010 e 2011), observamos que a gênese dos estudos curriculares nos Estados Unidos da América (EUA) teve uma ligação direta com a questão da industrialização, a imigração e o processo de ampliação da escolarização. Foi muito grande a influência de profissionais ligados à área da administração escolar para debater e racionalizar o processo de elaboração, implementação e avaliação do currículo (MALANCHEN, 2016). No Brasil, conforme Lopes e Macedo (2010, p. 13):

As primeiras preocupações com o currículo, no Brasil, datam dos anos 20. Desde então, até a década de 1980, o campo foi marcado pela transferência instrumental de teorizações americanas. Essa transferência centrava-se na assimilação de modelos para a elaboração curricular, em sua maioria de viés funcionalista, e era viabilizada por acordos

\footnotetext{
${ }^{4}$ Para saber mais ver MALANCHEN, (2016).
}

bilaterais entre os governos brasileiro e norte americano dentro do programa de ajuda à América Latina.

As autoras, explicam que no início dos estudos sobre currículo, dois movimentos tiveram destaque nos EUA: o eficientismo social, representado pelas ideias de Franklin Bobbit $^{5}$ e Ralph Tyler $^{6}$ e o progressivismo que teria como principal teórico John Dewey ${ }^{7}$. Posteriormente esses dois movimentos, vieram constituir base para uma teoria neutra de currículo que, de maneira geral, primaram em associar os objetivos da educação escolar visando formar mão de obra especializada para o mercado de trabalho (LOPES; MACEDO, 2010).

No final, o currículo seria somente uma questão de organização e racionalização, uma questão puramente neutra e técnica. Esses estudos são identificados no campo do currículo no Brasil, como teoria acrítica ou tecnicista, ou até mesmo teoria tradicional do currículo (MALANCHEN, 2016). Enfatizamos aqui, que mesmo utilizando a mesma nomenclatura da teoria pedagógica tradicional, a teoria do currículo conhecida como tradicional tem um momento diferente de elaboração e desenvolvimento: o de ampliação da abertura de escolas devido à industrialização e a necessidade de organizar estes espaços que foram abertos para um número maior da população a capacitação dos e adaptação dos indivíduos as necessidades das indústrias.

Em direção oposta, nos anos de 1970, como resultado dos movimentos de 1968, iniciase o debate crítico sobre currículo, tendo como principais representantes: Michel Apple, William Pinar, Michel Young, Henry Giroux, Basil Bernstein e Paulo Freire, etc. Na linha dos estudos nomeados como críticos ou contestadores do currículo existem diversas correntes como: reconceptualização,

\footnotetext{
${ }^{5}$ Foi professor de administração na Universidade de Chicago. É considerado um dos precursores dos estudos sobre currículo, sendo responsável pelo estabelecimento do currículo como campo de especialização na área da educação.

${ }^{6}$ Educador norte americano, que desenvolveu trabalhos com ênfase na avaliação escolar. Ficou conhecido principalmente pelo seu livro: Princípios básicos de currículo e ensino.

${ }^{7}$ Um dos grandes nomes da filosofia pragmatista e do movimento escolanovista que nos EUA ficou conhecido como educação progressiva.
} 
neomarxista ${ }^{8}$, fenomenológica, de políticas culturais e a Nova Sociologia da Educação (NSE), entre outras (MALANCHEN, 2016). Sobre as teorias críticas do currículo Silva (2009, p. 30) explica que:

As teorias críticas sobre o currículo, [...], começam por colocar em questão precisamente os pressupostos dos presentes arranjos sociais e educacionais. As teorias críticas desconfiam do status quo, responsabilizando-o pelas desigualdades e injustiças sociais. [...] as teorias críticas são teorias da desconfiança, questionamento e transformação radical. Para as teorias críticas o importante não é desenvolver técnicas de como fazer o currículo, mas desenvolver conceitos que nos permitam compreender o que o currículo faz.

Por fim teriam emergido de acordo com a classificação de Silva (2009), os estudos póscríticos que discutem outras questões além da ideologia e poder que os estudos críticos enfatizam. As teorias pós-críticas de currículo são marcadas por ideias de autores como: Peter Mclaren, Gilles Deleuze, Félix Guattari, Stuart Hall, Michel Foucault, Joe Kincheloe, e Paul Willis, com grande influência de estudos do campo da sociologia e da antropologia. Desse modo, as teorias pós-críticas, ressaltam a questão da diversidade cultural, do pluralismo de ideias, portanto, trabalham com ênfase no relativismo cultural e epistemológico (DUARTE, 2010).

Concomitante a esse contexto, diversos movimentos sociais têm lutado por seus direitos, feito reivindicações e defendido suas ideias. Os debates, realizados dentro dessa perspectiva, fizeram com que emergissem diversas questões em relação ao currículo escolar, tais como: diversidade cultural, valorização da subjetividade, deslocamento da discussão sobre classes sociais

\footnotetext{
${ }^{8}$ Neomarxismo vem sob a liderança do pensamento da Nova Esquerda. Muitos neomarxistas, como Herbert Marcuse foram filósofos, sociólogos e psicólogos. Esta abordagem tem vinculação com os movimentos estudantis na década de 1960.
}

para discussões sobre identidade, alteridade, diferença, cultura de cada grupo, gênero, raça, etnia, religião e orientação sexual.

Observamos que essa mudança no foco do "o que ensinar", tem fundamentos que se desdobram do pensamento pós-moderno dentro da educação escolar, mais precisamente a defesa de um currículo pós (ou "pós-currículo"), amparado no relativismo cultural existente nos debates sobre currículo nos últimos tempos. A agenda pós-moderna ${ }^{9}$ em sua configuração, é composta por diversas teorias que têm discursos que se perpassam como a negação do sujeito, da razão, da história, da totalidade e do conhecimento objetivo. Com essa defesa para os intelectuais "pós", tudo é resultado da compreensão subjetiva, da experiência pessoal e das interpretações dessa experiência. Postula-se a partir dessa compreensão que a realidade é somente o que cada um percebe ser.

Desse modo as concepções da realidade precisam ser niveladas, para que nenhuma seja considerada mais verdadeira que a outra. Em algumas variantes do Pós-modernismo defendese concepções um pouco menos individualistas do conhecimento e este é considerado uma construção cultural compartilhada por um grupo. Nesse caso, serão verdadeiras aquelas ideias que integrem a identidade do grupo, não cabendo qualquer juízo de valor externo a isso. Assim, para o pensamento pós-moderno, os critérios para distinção do que é verdadeiro ou falso são sempre relativos, sempre circunscritos à subjetividade individual ou do grupo/comunidade (WOOD, 1999; MORAES, 1996, FONTE, 2006; EAGLETON, 2005; NAGEL, 2009).

Entre as principais proposições do pensamento pós-moderno no campo da educação escolar está o Multiculturalismo, uma teoria que tem orientado grande parte dos pesquisadores que estudam o currículo escolar (CANEN, 2010; CORAZZA, 2010; MOREIRA; CANDAU, 2003). A questão multicultural aparece como alternativa que visa, por meio do currículo, corrigir problemas referentes à desvalorização de movimentos sociais e tem apoio nos estudos culturais dos anos 1990. Para os defensores do Multiculturalismo, o que deve ser analisado e denunciado é como discriminações relativas a questões de gênero, raça, etnia, classe e religião, afetam a construção do conhecimento, valores e identidades nas instituições escolares. Em meio a

\footnotetext{
${ }^{9}$ Para saber mais ver WOOD, (1999).
} 
estas questões ganha cada dia mais espaço o currículo numa perspectiva multicultural, portanto pautada no relativismo cultural e epistemológico. Como afirma Duarte (2006), a retórica pós-moderna coloca a educação diante de uma falsa escolha entre o etnocentrismo e o relativismo cultural. É como se só existissem essas duas alternativas e como se a escolha moral e politicamente correta só pudesse ser pelo relativismo cultural. $O$ patrimônio histórico e cultural da humanidade, o conhecimento objetivo e universal, é refutado apontado como: etnocêntrico, eurocêntrico, branco, masculino, discriminador, preconceituoso, opressor e colonizador.

Nessa perspectiva, o termo cultura, para os multiculturalistas, é uma forma geral de vida de um determinado grupo social, com interpretações e visões de mundo por este adotada. Os pesquisadores do multiculturalismo afirmam ainda que a inclusão dessa forma de cultura no currículo pode resultar em respeito e receptividade às culturas dos educandos, por mais desprestigiadas que sejam, pois afirmam ser necessário romper com o "daltonismo cultural" dentro do espaço escolar.

A retórica do multiculturalismo evidencia por si mesma o caráter problemático desse discurso por pelos menos duas grandes razões. A primeira é a incoerência entre o caráter supostamente crítico com que esse ideário se apresenta e o conformismo social que caracteriza sua atitude, já que o limite das lutas sociais é dado pela negação da perspectiva de superação do modo de produção capitalista. A segunda razão é o fato de que, admitindo-se essa visão de valorização da cultura dos grupos, a desvalorização da escola e do trabalho educativo significa, no limite, a possibilidade de extinção de um grupo social de grande importância para a história do mundo moderno, o dos professores (MALANCHEN, 2016).

Além da problemática da desvalorização da escola, do professor e do esvaziamento do currículo, temos outros problemas produzidos por esta visão multicultural. De acordo com Wood (1999), a questão da fragmentação das lutas da classe trabalhadora, por meio da organização individual dos grupos subalternos em movimentos sociais, é um ponto que merece atenção, ao analisarmos a "agenda pós". Para a autora, o Pós-modernismo, ao enfatizar as lutas fragmentadas de movimentos sociais, rejeita 0 conhecimento da totalidade, os valores universais, a racionalidade, a igualdade (na concepção liberal ou na socialista) e, de forma mais profunda, a concepção do marxismo de emancipação humana.

No campo da educação escolar, isso reflete como Oliveira (2008, p. 102) já nos anunciava e hoje observamos claramente, no discurso negacionista, presente mais do que nunca em tempos de pandemia do Covid-19:

[...] uma crescente
desqualificação da ciência,
do conceito e da própria
filosofia que sustenta a
visão de mundo e de
realidade [...]. Neste
sentido, colocando em
dúvida a existência da
realidade e da própria
ciência, estas filosofias
colocam em xeque a
necessidade da existência
da escola e do trabalho
escolar.

Quando se nega ou é posta em dúvida a possibilidade do conhecimento objetivo da realidade, é inevitável que o mesmo aconteça com a ideia de transformação dessa realidade a partir desse mesmo conhecimento. $O$ que se forma e passa a existir a partir disso é a negação do homem genérico universal, defendido pelo projeto socialista. $\mathrm{O}$ que ocorre, cada vez mais é a defesa do homem individual e particular, da prática da tolerância, da resiliência e da paz, que no final formam a insensibilidade contra todos os problemas que aumentam e afligem a nossa sociedade.

Reafirmamos que em nossa compreensão e análise, o que devemos combater não é a diversidade cultural, mas sim as diferenças que resultam das desigualdades sociais. De acordo com Malanchen (2016), não somos contra a valorização da diversidade de culturas, mas somos contra o relativismo que resulta de uma compreensão equivocada do respeito ao pluralismo e ao diverso, que acabam por relativizar a ciência e o conteúdo escolar, e desse modo acabam servindo para legitimar práticas pedagógicas esvaziadas de conteúdo, elaboração de currículos aligeirados e com um viés tecnicista como é o caso da BNCC (20172018), direcionados para um conteúdo pragmático pautado no saber fazer, sem o saber pensar. 
No ideário multicultural, a objetividade e a universalidade do conhecimento não são consideradas relevantes, visto que se tornaram um desrespeito às culturas populares que devem ser consideradas e valorizadas num currículo escolar. Esta defesa está pautada num outro discurso: o da humanização do capitalismo por meio de atitudes que valorizem a democracia política e cultural (MALANCHEN, 2016).

Enfatizamos aqui, que não queremos, de modo algum, criticar ou desvalorizar a luta de movimentos sociais contra as diversas formas de preconceito, discriminação e exclusão social e cultural. Não é objetivo deste texto a análise das características desses movimentos, suas conquistas, seus avanços e suas contradições. Limitamo-nos a problematizar as implicações para os currículos escolares, da adoção generalizada do relativismo cultural.

Desse modo concordamos com Fonte (2012, p. 2) que é preciso "descartar a possibilidade de que ser contra o relativismo cultural e a celebração das diferenças, significa ser contra a diversidade de culturas existentes". $\mathrm{Na}$ teoria marxista, compreender a totalidade como universalidade, significa compreender a relação de contradições entre seres diversos, ou seja, para a universalidade existir há a necessidade do diverso. Isto representa a compreensão da realidade por contradição: ela é unidade e também diversidade (MALANCHEN, 2016).

Concluímos este item afirmando a necessidade de superação do multiculturalismo no campo educacional, e, em particular, no campo dos estudos sobre o currículo escolar. As contradições e inconsistências da abordagem multicultural a tornam uma grande aliada das forças sociais conservadoras e negacionistas, a despeito de, no plano das aparências, o multiculturalismo ser identificado por muitos dos seus defensores e críticos como uma linha de pensamento de esquerda.

\section{PEDAGOGIA HISTÓRICO-CRÍTICA E A ORGANIZAÇÃO DE UMA TEORIA CURRICULAR MARXISTA}

A principal defesa da Pedagogia Histórico-Crítica é de que a escola deve ser um espaço no qual 0 trabalho pedagógico desenvolvido possibilite que 0 universal do gênero humano se encontre com o singular e os diversos modos de ser humano, produzindo assim a humanidade historicamente acumulada
(SAVIANI, 2003a). Defendemos, portanto que o acesso ao saber sistematizado, ao saber objetivo, possibilita o combate ao preconceito, ao desmitificar crenças e evidenciar a superficialidade de alguns argumentos e atitudes em relação a alguns grupos sociais.

Com essa compreensão, observamos que um desafio a ser enfrentado na difusão da Pedagogia Histórico-Crítica é a difusão da concepção de mundo materialista histórica e dialética, sem o que, a própria discussão sobre o papel do conhecimento na formação humana corre o risco de não ir além de vagas afirmações sobre a necessidade de desenvolvimento do pensamento autônomo e crítico. Essa difusão além de perpassar a elaboração de currículos escolares que se contrapõem a BNCC (BRASIL, 2017; BRASIL, 2018), também precisa fazer parte de projetos de cursos de formação inicial e continuada de professores. Pois sem professores formados numa perspectiva Histórico-Crítica fica impossível elaborar, implementar e superar políticas públicas educacionais e currículos conservadores e/ou tecnicistas.

Enfatizamos, assim, que o caminho para a organização de um currículo a partir da Pedagogia Histórico-Crítica é o de tomar como eixo norteador de nossa concepção de mundo materialista histórico e dialética, aquilo que é próprio do ser humano: o trabalho, entendido como atividade especificamente humana de transformação consciente da realidade natural e social (MALANCHEN, 2016).

De acordo com os autores que fundamentam a teoria Histórico-crítica, é de fundamental importância possibilitar o acesso aos bens não só materiais, mas também intelectuais produzidos até o momento pela humanidade, como forma de constituir um ser humano com aptidões e funções mais elevadas, concorrendo para a emancipação humana. O acesso aos bens intelectuais mais desenvolvidos, como a ciência, a arte e a filosofia, na sociedade contemporânea, não podem se concretizar para a totalidade da população a não ser por meio da educação escolar.

Nesse processo, compreendemos que as várias disciplinas e seus conteúdos curriculares têm o papel de promover o desenvolvimento psíquico dos alunos. O pensamento conceitual do sujeito, o raciocínio lógico, por fim, as funções psicológicas superiores são desenvolvidas de forma integral, a partir da organização e transmissão do conhecimento cientifico pelo 
professor, que deve ser apropriado pelo indivíduo (VYGOTSKI, 1993).

Como a escola, em nossa sociedade é, a princípio, a instituição mais organizada para transmitir o conhecimento sistematizado, pode provocar 0 desenvolvimento das funções psicológicas dos indivíduos a partir da apropriação do patrimônio cultural acumulado. Quando a escola/currículo se propõe a conduzir o aluno ao pensamento conceitual, possibilita maiores condições para o conhecimento da realidade objetiva.

Ressaltamos por outro lado, que o professor não deve desconsiderar os conceitos espontâneos, cotidianos, que o aluno já possui, mas o objetivo do trabalho educativo não é o de limitar o pensamento do aluno a esses conceitos. Ao contrário, trata-se de superar por incorporação esse nível mais elementar do pensamento, alçando-o a níveis mais complexos e elevados que só podem ser alcançados por meio do pensamento abstrato, isto é, dos conceitos científicos. Duarte $(2000$, p. 87 ) assinala que o conhecimento construído pelo pensamento científico "a partir da mediação do abstrato não é uma construção arbitrária da mente, não é o que o fenômeno parece ser ao indivíduo, esse conhecimento é a captação, pelo pensamento, da essência da realidade objetiva" (DUARTE, 2000). Deste modo, a apropriação dos conceitos científicos promove o desenvolvimento das funções psicológicas de maneira a permitir a compreensão dos processos essenciais da realidade, condição necessária, ainda que não suficiente, para sua transformação pela prática social (MALANCHEN, 2016).

Portanto, a defesa de uma Teoria Histórico-crítica Curricular, é a de que busquemos na cultura produzida pela humanidade, o que há de mais rico, o que existe de mais desenvolvido para transmitir às novas gerações. Dessa forma, a socialização da riqueza intelectual universal pela escola situa-se num contexto mais amplo, o de luta pela socialização da riqueza humana como um todo e, mais precisamente, pela superação da propriedade privada dos meios de produção (MALANCHEN, 2016). A escola para se colocar em oposição à alienação produzida pela sociedade de classes, precisa atuar naquilo que caracteriza sua especificidade, isto é, nas palavras de Saviani (2003b), "a socialização do saber sistematizado". Como explicam Martins e Pasqualini

(2020, p. 29):
Sob este enfoque, caberá

à educação escolar corroborar uma formação omnilateral,

proporcionando condições para os máximos alcances do desenvolvimento psíquico e de sua qualidade maior, a consciência (aspecto ontológico), tendo em vista tornar a realidade inteligível (aspecto epistemológico), para que nela os sujeitos possam intervir para preservar o que precisa ser preservado e transformar o que precisa ser superado, no que se inclui a sociedade de classes (aspecto éticopolítico).

Desse modo, temos clareza de quais conhecimentos devem compor os currículos escolares nas escolas públicas, para os filhos da classe trabalhadora, mas também sabemos que para isso se concretizar precisamos de muito trabalho na formação política e pedagógica dos professores. Enfatizamos, portanto, a necessidade de melhores condições de trabalho para os professores da educação básica iniciando com urgente ampliação da carga horária de estudos no horário de trabalho, a adequação dos prédios escolares, bibliotecas e materiais pedagógicos enquanto luta permanente. Endossamos essa luta requerendo maiores investimentos em educação para a educação e o pleno desenvolvimento dos sujeitos, a valorização salarial, sendo contrários a PEC 55 (2016) que congela os investimentos para o campo educacional por vinte anos. Do mesmo modo, é preciso o fortalecimento da luta pela educação integral para os estudantes, com conteúdos e disciplinas que possam garantir o aprendizado e o desenvolvimento das funções psicológicas e consequentemente, a formação de um pensamento conceitual que realmente analise e compreenda a realidade e suas contradições.

Não entendemos essa luta como isolada, e sim conjunta à luta por melhores condições de vida para todos. Para a escola, especificamente, direcionamos nossos esforços em reivindicar um currículo que realmente 
possibilite a emancipação humana. Conforme Malanchen e Santos (2020, p. 16):

A nossa luta e resistência pautada nos fundamentos da Pedagogia Históricocrítica é o de se contrapor a um projeto de nação despolitizado atrelado a outros projetos como: Escola sem Partido; Educação domiciliar, Educação a Distância, Residência Pedagógica, Militarização das escolas, Reforma da Previdência, Reforma do Ensino Médio, extinção de cursos de Filosofia e Sociologia, a PEC 55 que congelou investimentos na educação, saúde e ação social. Um projeto do capital que não investe em cultura, em educação do pensamento crítico, um projeto como afirma Newton Duarte do "Obscurantismo beligerante".

Não bastasse a dificuldade que o Brasil enfrenta, talvez, sua maior crise sanitária devido a pandemia do Covid- $19^{10}$, na qual a ciência vem sendo depreciada e posta em xeque, sendo que a vacina e a saúde são negadas para a maioria da população, há a imposição de uma BNCC com fundamentos tecnicistas para as escolas e o ensino remoto, junto ao aumento da precarização do trabalho de professores e da falta de acesso de milhões de indivíduos a escola é naturalizado. Fica cada vez mais claro que precisamos nos unir esclarecer e nos organizar enquanto classe trabalhadora e lutar pela vida, pelas novas gerações.

Dispor-se em lutar nesse viés é empenhar-se em organizar a transformação social, com a perspectiva de uma sociedade sem classes, portanto realmente justa e igualitária, pondo fim no capitalismo e na sua ânsia pelo lucro a qualquer preço.

\footnotetext{
${ }^{10} \mathrm{Na}$ data que finalizo esse texto (30/06/21), infelizmente atingimos mais de 515.000 mortes registradas por Covid-19 em nosso país. Difícil aceitar que pessoas continuem morrendo de uma doença que já tem vacina, que a ciência já possibilitou uma alternativa. A morte e a vida no capitalismo são questões determinadas por decisões políticas.
}

No contexto atual de tanta barbárie, o professor Dermeval Saviani, nos relembra da necessidade de organizarmos um movimento amplo de resistência:

Diante desse quadro fica evidente a necessidade de se organizar um amplo e consistente movimento de resistência contra o governo antipopular e antinacional de modo geral e, especificamente, no campo da educação. Resistência Ativa, como você bem observou. Volto, pois, a advogar a Estratégia da Resistência Ativa que propus na Conclusão do livro sobre a atual Lei de Diretrizes e Bases da Educação Nacional, cuja 13a edição foi lançada em 2016, ao ensejo dos 20 anos da aprovação da LDB, atualizada e ampliada com um novo capítulo analisando as 39 leis que a modificaram. $O$ que chamei de resistência ativa implica dois requisitos: a) que seja coletiva, pois as resistências individuais não têm força para se contrapor ao poder dominante exercido pelo governo; b) que seja propositiva, isto é, que seja capaz de apresentar alternativas às medidas do governo e de seus asseclas. Essa forma de resistência é indispensável como estratégia de luta por uma escola livre das ingerências privadas balizadas pelos interesses do mercado. 0 desenvolvimento da consciência social dos trabalhadores da cidade e do campo como premissa para a ação política e ideológica eficaz implica dois aspectos, de preferência organicamente 
articulados entre si. Trata-se da educação, com destaque para a forma escolar, e a própria ação das massas organizadas. A educação escolar é o meio mais adequado para a apropriação, pelos trabalhadores, das conquistas históricas da humanidade que lhes aguçarão a consciência da necessidade de intervir praticamente para dar continuidade ao processo histórico conduzindo-o a um novo patamar.

(DUARTE; SAVIANI, 2019, p. 5).

Como questionamos em outro artigo publicado no ano de 2020: conseguiremos impedir tanta destruição e mortes, promovidos pelo atual governo antinacional e seus aliados? Não temos essa resposta no momento, mas podemos e devemos continuar denunciando e realizando os devidos esclarecimentos, descortinando o que está acontecendo e o que ainda pode acontecer pós-pandemia e que esses prenúncios, não passem sem o crivo da nossa luta e crítica em prol de uma educação de qualidade, e a defesa da ciência e da vida (MALANCHEN, 2020).

\section{REFERÊNCIAS}

BRASIL. Ministério da Educação. Resolução CNE/CP no 2, de 22 de dezembro de 2017. Institui e orienta a implantação da Base Nacional Comum Curricular a ser respeitada obrigatoriamente ao longo das etapas e respectivas modalidades no âmbito da Educação Básica. Versão Final. Brasília, DF: MEC, 2017.

BRASIL. Ministério da Educação. Resolução CNE/CP № 4, de 17 de dezembro de 2018. Institui a Base Nacional Comum Curricular na Etapa do Ensino Médio (BNCC-EM), como etapa final da Educação Básica, nos termos do artigo 35 da LDB, completando o conjunto constituído pela BNCC da Educação Infantil e do Ensino Fundamental, com base na Resolução CNE/CP no 2/2017, fundamentada no Parecer CNE/CP no 15/2017. Versão Final. Brasília, DF: MEC, 2018. (Ensino Médio).
BRASIL. Ministério da Educação. Resolução CNE/CP no 2, de 20 de dezembro de 2019. Define as Diretrizes Curriculares Nacionais para a Formação Inicial de Professores para a Educação Básica e institui a Base Nacional Comum para a Formação Inicial de Professores da Educação Básica (BNC-Formação). Brasília, DF: MEC, 2019.

BRASIL. Ministério da Educação. Resolução CNE/CP № 1, de 27 de outubro de 2020. Dispõe sobre as Diretrizes Curriculares Nacionais para a Formação Continuada de Professores da Educação Básica e institui a Base Nacional Comum para a Formação Continuada de Professores da Educação Básica (BNC-Formação Continuada). Brasília, DF: MEC, 2020.

CANEN, A. Sentidos e dilemas do multiculturalismo: desafios curriculares para o novo milênio. In: LOPES, A. C.; MACEDO, E. (Orgs). Currículo: debates contemporâneos. 3. ed. SP: Cortez, 2010.

CORAZZA, S. M. Diferença pura de um póscurrículo. In: LOPES, A. C.; MACEDO, E. (Orgs). Currículo: debates contemporâneos. 3. ed. SP: Cortez, 2010.

DUARTE, N. A anatomia do homem é a chave da anatomia do macaco: A dialética em Vigotski e em Marx e a questão do saber objetivo na educação escolar. Educação e Sociedade, Campinas, n. 71, p. 79-115, jul., 2000. https://doi.org/10.1590/s010173302000000200004

DUARTE, N. A contradição entre universalidade da cultura humana e o esvaziamento das relações sociais: por uma educação que supere a falsa escolha entre etnocentrismo ou relativismo cultural. Educação e Pesquisa, São Paulo, v.32, n.3, p. 607-618, set./dez. 2006. https://doi.org/10.1590/S1517$\underline{97022006000300012}$

DUARTE, N. O debate contemporâneo das teorias pedagógicas. In: MARTINS, L. M.; DUARTE, N. (Org.). Formação de professores: limites contemporâneos e alternativas necessárias. São Paulo: Cultura Acadêmica, 2010.

DUARTE, N.; SAVIANI, D. Entrevista com o professor Dermeval Saviani e a pedagogia histórico-crítica na atualidade. Colloquium 
Humanarum. v. 16, n. 2, p. 4-12, 2019. DOI https://doi.org/10.5747/ch.v16i2.3121

EAGLETON, Terry. Depois da teoria: um olhar sobre os estudos culturais e o pós-modernismo. Rio de Janeiro: Civilização Brasileira, 2005.

FONTE, S. S. D. As fontes heideggerianas do pensamento pós-moderno. 2006. 233 f. Tese (Doutorado em Educação) - Universidade Federal de Santa Catarina, 2006.

FONTE, S. S. D. Escola, unidade e diversidade: reflexões a partir de Karl Marx. In: REUNIÃO ANUAL DA ANPED, 35., 2012. Anais [...]. Recife: Centro de Convenções do Hotel Armação, 2012. p. 1-20. Disponível em: http://35reuniao.anped.org.br/trabalhos/125gt17. Acesso em: 12 ago. 2013.

GOODSON, I. F. Currículo: teoria e história. Petrópolis, RJ: Vozes, 1995.

LOPES, A. C.; MACEDO, E. I. O pensamento curricular no Brasil. In: LOPES, A. C.; MACEDO, E. (Orgs). Currículo: debates contemporâneos. 3. ed. SP: Cortez, 2010.

LOPES, A. C.; MACEDO, E. Teorias do currículo. São Paulo: Cortez, 2011.

MALANCHEN, J. Cultura, conhecimento e currículo: contribuições da pedagogia históricocrítica. Campinas, SP: Autores Associados, 2016.

MALANCHEN, J. Oportunismo do capital e a precarização da educação pública via EAD: análise a partir da Pedagogia Histórico-Crítica. Revista educação e cotidiano Ressignificado online, v. 1 , n. 4, 2020. Disponível em: https://rpcr.com.br/index.php/revista rpcr/articl e/view/1. Acesso em: 12 abr. 2021.

MALANCHEN, J.; SANTOS, S. A. Políticas e reformas curriculares no Brasil: perspectiva de currículo a partir da pedagogia histórico-crítica versus a base nacional curricular comum e a pedagogia das competências. Campinas/SP. Revista HISTEDBR On-line, v. 20, 2020. DOI https://doi.org/10.20396/rho.v20i0.8656967

MARTINS, L. M; PASQUALINI, J. C. O currículo escolar sob enfoque histórico-crítico: aspectos ontológico, epistemológico, ético-político e pedagógico. Nuances, v. 31, n. 1, p. 23-37, dez., 2020. DOI 10.32930/nuances.v31iesp.1.8280.

MORAES, M. C. M. de. Os pós-ismos e outras querelas ideológicas. Perspectiva, Florianópolis, n. 24, 1996. Disponível em: https://periodicos.ufsc.br/index.php/perspectiva Larticle/view/10856. Acesso em: 10 nov. 2012.

MOREIRA, A. F. B.; CANDAU, V. M. Educação escolar e cultura (s): construindo caminhos. Revista Brasileira de Educação, n. 23, p. 156-168, 2003. DOI https://doi.org/10.1590/S141324782003000200012

NAGEL, L. H. O homem em sua humanidade na perspectiva do Multiculturalismo. In: CONGRESSO INTERNACIONAL DE PSICOLOGIA/ X SEMANA DE PSICOLOGIA DA UEM, 4., 2009, Maringá. Anais [...]. Maringá: Universidade Estadual de Maringá, 2009.

OLIVEIRA, M. A. de. As bases filosóficas e epistemológicas de alguns projetos de educação do campo: do pretendido marxismo à aproximação ao ecletismo pós-moderno. 2008. 481 f. Tese (Doutorado em Educação) Universidade Federal do Paraná, UFPR, 2008.

SAVIANI, N. Saber escolar, currículo e didática: problemas da unidade conteúdo/método no processo pedagógico. 3. ed. Campinas, SP: Autores Associados, 2000.

SAVIANI, D. Pedagogia histórico-crítica: primeiras aproximações. 8. ed. Campinas, SP: Autores Associados, 2003(a).

SAVIANI, D. Escola e democracia. 36. ed. Campinas, SP: Autores Associados, 2003(b).

SILVA, T. T. Documentos de identidade: uma introdução às teorias do currículo. 3. ed. Belo Horizonte: Autêntica, 2009.

WOOD, E. M. O que é a agenda "pós-moderna"? In: WOOD, E. M.; FOSTER, J. B. (orgs). Em defesa da história: marxismo e pós-modernismo. Rio de Janeiro: Ed. Jorge Zahar, 1999.

VYGOTSKI, L. S. Obras Escolhidas II. Madrid: Centro de publicaciones Del M.E.C. y Visor Distribuciones, 1993. 